\title{
Postmarketing safety experience with edoxaban in Japan for thromboprophylaxis following major orthopedic surgery
}

This article was published in the following Dove Press journal:

Vascular Health and Risk Management

5 October 2013

Number of times this article has been viewed

\section{Yasufumi Kuroda' \\ Chie Hirayama ${ }^{2}$ \\ Hitoshi Hotoda ${ }^{2}$ \\ Yasuhiro Nishikawa ${ }^{2}$ \\ Akinori Nishiwaki ${ }^{2}$}

'Daiichi Sankyo Pharma Development, Edison, NJ, USA; ${ }^{2}$ Daiichi Sankyo Company, Limited, Tokyo, Japan
Correspondence: Yasufumi Kuroda Daiichi Sankyo Pharma Development, 399 Thornall St, Edison, NJ, USA, 08837

Tel +l 7325904949

Fax +l 7329065690

Emailykuroda@dsi.com
Purpose: Edoxaban is an oral, once-daily, selective, direct factor Xa inhibitor approved in Japan for the prevention of venous thromboembolism following major orthopedic surgery. Currently, edoxaban is in Phase III clinical development for the prevention of stroke and systemic embolic events in patients with atrial fibrillation, and for the treatment and prevention of recurrences of venous thromboembolism. This report describes the adverse drug reactions (ADRs) spontaneously reported during early postmarketing phase vigilance from the time of its commercial launch in Japan.

Materials and methods: All spontaneously reported ADRs following edoxaban use received by Daiichi Sankyo during early postmarketing phase vigilance from July 19, 2011, to January 18, 2012, were entered into the safety database and included in this review. Approximately 20,000 patients were estimated to have been treated with edoxaban.

Results: The mean age of patients was 74.2 years, their mean weight was $59.4 \mathrm{~kg}$, and approximately $70 \%$ were female. A total of 67 ADRs were reported in 56 patients, of which the majority included bleeding events (51 ADRs in 42 patients). Of these, 15 ADRs (in 14 patients) were serious, including cerebral hemorrhage $(n=1)$, gastric hemorrhage $(n=2$; gastric hemorrhage $[n=1]$ and gastric ulcer hemorrhage $[n=1])$, and surgical-site hemorrhage ( $n=12$; hemorrhage $[n=6]$, subcutaneous hemorrhage $[n=3]$, wound hemorrhage $[n=2]$, and wound hematoma $[n=1])$. Most ADRs occurred within the first week of treatment and there were no fatalities. Nonserious ADRs associated with bleeding that occurred in $>1$ patient included subcutaneous hemorrhage $(n=9)$, wound hemorrhage $(n=5)$, postprocedural hematoma $(n=4)$, anemia $(n=4)$, and hemarthrosis $(n=3)$. Other nonserious ADRs not associated with bleeding and occurring in $>1$ patient included abnormal hepatic function $(n=4)$ and diarrhea $(n=2)$.

Conclusion: Safety data from the first 6 months of postmarketing experience with edoxaban did not identify any unforeseen safety signals, consistent with the known safety profile of edoxaban.

Keywords: edoxaban, venous thromboembolism, factor Xa, early postmarketing phase vigilance, thromboprophylaxis, spontaneous reporting

\section{Introduction}

Venous thromboembolism (VTE) has an annual incidence in the general population of approximately 1 per 1,000 people. ${ }^{1}$ The incidence of VTE in Japan following orthopedic surgery is lower than in Europe and North America, though it has increased in the last 40 years. ${ }^{2}$ VTE can be fatal, ${ }^{3}$ may lead to chronic thromboembolic pulmonary hypertension, ${ }^{4}$ and is a risk factor for subsequent arterial cardiovascular events, such as myocardial infarction and stroke. ${ }^{5}$ Major risk factors for VTE include thrombophilia, history of deep vein thrombosis (DVT), older 
age, surgery, and obesity. ${ }^{1,3,6}$ Patients undergoing major orthopedic surgery, including total hip arthroplasty (THA), total knee arthroplasty (TKA), and hip fracture surgery (HFS), have an especially high risk for VTE; ${ }^{7}$ DVT occurs in approximately $40 \%$ to $60 \%$ of patients who do not receive thromboprophylaxis after major orthopedic surgery. ${ }^{8}$

Edoxaban is an oral, reversible, selective, direct factor Xa inhibitor approved in Japan (LIXIANA ${ }^{\circledR}$; Daiichi Sankyo Company, Limited, Tokyo, Japan) as a 30-mg once-daily dose for the prevention of VTE following TKA, THA, and HFS. ${ }^{9}$ Edoxaban is also in Phase III development for the treatment and prevention of recurrences of VTE, ${ }^{10}$ and for the prevention of stroke and systemic embolism in patients with atrial fibrillation. ${ }^{11}$ Preclinical studies demonstrated that edoxaban produces a dose-dependent inhibition of thrombin generation and thrombus formation. ${ }^{12}$ In doseranging studies for the prevention of DVT following TKA or THA, edoxaban demonstrated dose-dependent reductions in VTE with a low incidence of bleeding events across dosing groups. ${ }^{13,14}$ Phase III clinical trials ${ }^{15-17}$ demonstrated the efficacy and safety of edoxaban in patients requiring VTE prevention after major orthopedic surgery, leading to its approval in Japan. ${ }^{9}$

According to its approved indication and product label in Japan, edoxaban use should be restricted to hospitalized postoperative patients, with the optimum duration of therapy based upon the patient's risks of VTE and bleeding. ${ }^{9}$ Administration of the initial dose of edoxaban should only proceed after confirmation that no bleeding occurred within 12 hours postsurgery, and at least 2 hours following removal of an epidural catheter or after lumbar puncture. For patients with moderate renal impairment (creatinine clearance $\left[\mathrm{CL}_{\mathrm{CR}}\right] \geq 30 \mathrm{~mL} /$ minute to $<50 \mathrm{~mL} /$ minute), a dose reduction to $15 \mathrm{mg}$ once daily should be considered after evaluation of the patient's risk of VTE against their risk of bleeding. However, edoxaban use is contraindicated in patients with severe renal impairment $\left(\mathrm{CL}_{\mathrm{CR}}<30 \mathrm{~mL} /\right.$ minute $)$ due to limited clinical data.

Taking these precautions into consideration, monitoring adverse drug reactions (ADRs), particularly bleeding events, following initial drug approval becomes especially important to better understand the safety profile of edoxaban. Therefore, postmarketing surveillance was performed in compliance with early postmarketing phase vigilance (EPPV) guidelines ${ }^{18}$ to assure the safety of edoxaban after release into the Japanese market. Here, we report the results of EPPV conducted from July 19, 2011, through January 18, 2012.

\section{Materials and methods}

\section{Patients and methods}

The precise number of edoxaban prescriptions, as well as the number and demographics of patients exposed to edoxaban during EPPV are unknown. Therefore, distribution data utilizing shipping volume of edoxaban between its commercial launch in Japan and at the end of the EPPV period were used. During the EPPV period, a total of 279,940 tablets were distributed. Assuming a dosing period per patient of 14 days regardless of dosage strength, the number of patients who were exposed to edoxaban was estimated to be approximately 20,000 (calculated as 279,940 tablets/14 days $=19,996$ [approximately 20,000 patients]). Therefore, the approximate number of edoxaban prescriptions was also 20,000 .

Daiichi Sankyo Company, Limited collected individual ADRs as spontaneous reports, and coded those ADRs according to the System Organ Class and Preferred Terms of the Medical Dictionary for Regulatory Activities (MedDRA/J version 14.1). ${ }^{19}$ The categorization of the seriousness of the ADRs was consistent with the definitions and terminology associated with the ICH Harmonised Tripartite Guideline. Post-Approval Safety Data Management: Definitions and Standards for Expediting Reporting $E 2 D$ document. ${ }^{20}$ Serious adverse events or reactions were characterized as any untoward medical occurrence that at any dose resulted in death; was life-threatening; required inpatient hospitalization or resulted in prolongation of existing hospitalization; resulted in persistent or significant disability or incapacity; was a congenital anomaly/birth defect; or was considered a medically important event or reaction. $^{20}$

\section{Results \\ Patient demographics}

Most patients reporting ADRs were female (39/56; 69.6\%). The average age of patients with ADRs was 74.2 years, and their average weight was $59.4 \mathrm{~kg}$. The majority of orthopedic surgeries that were performed in these patients were TKA $(29 / 56 ; 51.8 \%)$, followed by THA $(13 / 56 ; 23.2 \%)$ and HFS $(12 / 56 ; 21.4 \%)$. The type of surgery in two patients was unknown $(3.6 \%)$.

\section{Adverse drug reactions}

There were 67 ADRs reported in 56 patients, the majority of which were bleeding events (Table 1). A total of 
Table I Summary of adverse drug reactions by the Medical Dictionary for Regulatory Activities System Organ Class and Preferred Terms

\begin{tabular}{|c|c|c|c|c|}
\hline \multirow{2}{*}{$\begin{array}{l}\text { Medical Dictionary for Regulatory } \\
\text { Activities System Organ Class }\end{array}$} & \multirow{2}{*}{$\begin{array}{l}\text { Medical Dictionary for Regulatory } \\
\text { Activities Preferred Terms }\end{array}$} & \multicolumn{2}{|c|}{ Number of adverse drug reactions (ADRs) } & \multirow[t]{2}{*}{ Total } \\
\hline & & Serious & Nonserious & \\
\hline Blood and lymphatic system disorder & Anemia & & 4 & 4 \\
\hline Nervous system disorders & Cerebral hemorrhage & 1 & & 1 \\
\hline \multirow[t]{2}{*}{ Vascular disorders } & Embolism venous & & 1 & I \\
\hline & Hemorrhage & 6 & 1 & 7 \\
\hline \multirow[t]{8}{*}{ Gastrointestinal disorders } & Diarrhea & & 2 & 2 \\
\hline & Feces discolored & & I & I \\
\hline & Gastric hemorrhage & I & & I \\
\hline & Gastric ulcer hemorrhage & 1 & & 1 \\
\hline & Gastrointestinal hemorrhage & & 1 & I \\
\hline & Gingival bleeding & & I & I \\
\hline & Hematemesis & & I & I \\
\hline & Hematochezia & & I & I \\
\hline \multirow[t]{4}{*}{ Hepatobiliary disorders } & Hepatic function abnormal & & 4 & 4 \\
\hline & Hyperbilirubinemia & & I & I \\
\hline & Jaundice & & I & I \\
\hline & Liver disorder & & 1 & I \\
\hline \multirow[t]{2}{*}{ Skin and subcutaneous tissue disorders } & Hemorrhage subcutaneous & 3 & 9 & 12 \\
\hline & Rash & & I & 1 \\
\hline Musculoskeletal and connective & Hemarthrosis & & 3 & 3 \\
\hline tissue disorders & Joint swelling & & I & I \\
\hline Renal and urinary disorders & Hematuria & & 1 & 1 \\
\hline Reproductive system and breast & Metrorrhagia & & 1 & I \\
\hline $\begin{array}{l}\text { General disorders and administration } \\
\text { site conditions }\end{array}$ & Edema & & I & 1 \\
\hline \multirow[t]{5}{*}{ Investigations } & Alanine aminotransferase increased & & 1 & I \\
\hline & Aspartate aminotransferase increased & & 1 & I \\
\hline & Hemoglobin decreased & & 1 & I \\
\hline & Liver function test abnormal & & I & I \\
\hline & Platelet count increased & & I & I \\
\hline Injury, poisoning, and procedural & Subcutaneous hematoma & & I & 1 \\
\hline \multirow[t]{3}{*}{ complications } & Wound hemorrhage & 2 & 5 & 7 \\
\hline & Postprocedural hematoma & & 4 & 4 \\
\hline & Wound hematoma & $\mathrm{I}$ & & I \\
\hline Total & & 15 & 52 & 67 \\
\hline
\end{tabular}

Note: This research was originally published as an abstract in Blood. Kuroda Y, Hotoda H, Nishikawa Y, and Nishiwaki A. Post-Marketing Safety Experience with Edoxaban in Japan for Thromboprophylaxis Following Major Orthopedic Surgery. Blood. 2012;120:Abstract 4697. (C) the American Society of Hematology. ${ }^{23}$

51 bleeding ADRs in 42 patients were reported. Of these, 15 events (in 14 patients) were considered serious. All serious ADRs were bleeding events, which included cerebral hemorrhage $(n=1)$, gastric hemorrhage $(n=2$; reported as gastric hemorrhage $[n=1]$ and gastric ulcer hemorrhage $[n=1])$, and surgical site hemorrhage $(n=12$; reported as hemorrhage $[n=6]$, subcutaneous hemorrhage $[n=3]$, wound hemorrhage [ $n=2]$, and wound hematoma $[n=1]$ ). All serious cases of bleeding ADRs resolved or improved. Nonserious ADRs associated with bleeding that occurred in more than one patient included subcutaneous hemorrhage $(n=9)$, wound hemorrhage $(n=5)$, postprocedural hematoma $(n=4)$, anemia $(n=4)$, and hemarthrosis $(n=3)$. Seven of the 15 serious bleeding events required transfusion and were classified as wound hemorrhage $(n=2)$, hemorrhage $(n=2)$, gastric hemorrhage $(n=1)$, subcutaneous hemorrhage $(n=1)$, and gastric ulcer hemorrhage $(\mathrm{n}=1)$.

Most bleeding ADRs occurred within the first week of treatment (Figure 1). The onset of bleeding ADRs peaked at day 2. A description of cases of bleeding ADRs classified by sex, age, body weight, and $\mathrm{CL}_{\mathrm{CR}}$ can be found in Table 2 . When classified by sex, the number of cases of bleeding ADRs was highest in females (33/42; 78.6\%). Approximately 55\% (23/42) of bleeding ADRs were reported in patients 75 years of age or older. When classified by body weight, $50.0 \%(21 / 42)$ had a body weight less than $60 \mathrm{~kg}$. The majority of bleeding ADRs $(76.2 \% ; 32 / 42)$ occurred in patients with $\mathrm{CL}_{\mathrm{CR}} \geq 50 \mathrm{~mL} /$ minute. 


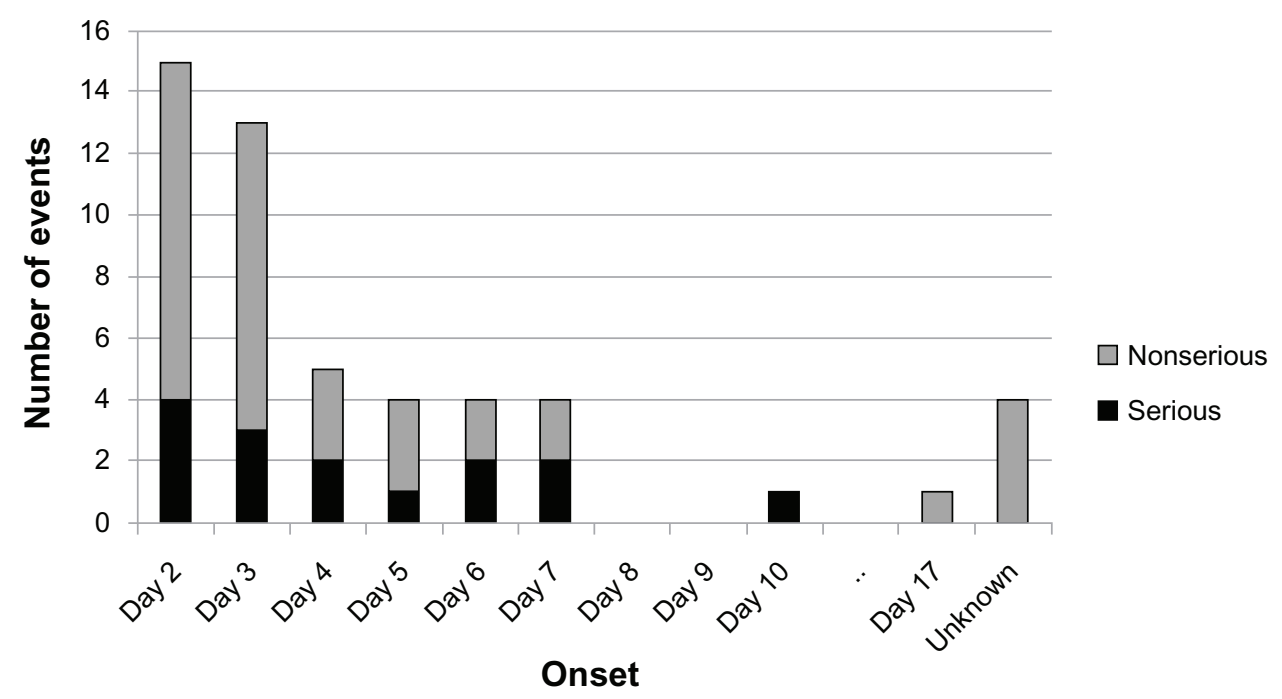

Figure I Bleeding adverse drug reactions by day of onset (number of events). Note: The initial dose was administered on day I.

Nonserious ADRs not associated with bleeding and occurring in more than one patient were abnormal hepatic function $(n=4)$ and diarrhea $(n=2)$. There were no serious hepatic ADRs or fatal cases reported.

\section{Discussion}

Identifying and analyzing the postmarketing risks for newlyapproved drugs are essential to ensure that the risk of potential adverse events has been thoroughly examined. The most commonly reported ADRs during EPPV for edoxaban were bleeding events. The majority of the serious bleeding cases were considered to be associated with the surgical site. All patients with serious bleeding ADRs recovered. The majority of bleeding cases were in patients who were 75 years of age or older, or who had a $\mathrm{CL}_{\mathrm{CR}}$ of $\geq 50 \mathrm{~mL} /$ minute. The tendency of these bleeding ADRs reflected the populations that were exposed. A study performed by Nagase et $\mathrm{al}^{21}$ retrospectively identified 27,542 patients who underwent THA or TKA in Japan by using the Japanese Diagnosis Procedure Combination administrative claims database. The patient demographics reported in our study are similar to those reported in the Nagase et $\mathrm{al}^{21}$ study, which demonstrated that in the overall population of patients who underwent TKA or THA, most patients were female (83.4\%) and the average age was 69.9 years. It should be noted, however, that the Nagase et $\mathrm{al}^{21}$ retrospective analysis collected data during a 1-year time period from 2007 to 2008, whereas our data was obtained during a 6-month period from 2011 to 2012. Also, the Nagase study only included patients with TKA and THA, and does not encompass patients who underwent HFS, while our study included HFS patients. Lastly, the Nagase et $\mathrm{a}^{21}$ study reported patient data from a national administrative claims database, whereas our study included patient data collected from voluntary, spontaneously reported cases of ADRs.

The EPPV period following the launch of edoxaban in Japan did not reveal any ADRs that had not already been observed during the drug approval process. The ADRs reported during the EPPV are consistent with the results from the Studying Thrombosis After Replacement Surgery (STARS) Phase III clinical trials ${ }^{15-17}$ that led to the approval

Table 2 Cases of bleeding adverse drug reactions by sex, age, body weight, and $\mathrm{CL}_{\mathrm{CR}}$

\begin{tabular}{|c|c|c|c|c|c|c|c|c|c|c|c|c|c|}
\hline \multirow{2}{*}{$\begin{array}{l}\text { Type of } \\
\text { surgery }\end{array}$} & \multicolumn{2}{|l|}{ Sex } & \multicolumn{3}{|c|}{ Age (years) } & \multicolumn{4}{|c|}{ Body weight (kg) } & \multicolumn{4}{|c|}{$\mathrm{CL}_{\mathrm{CR}}$ (mL/minute) } \\
\hline & $\mathbf{M}$ & $\mathbf{F}$ & $<65$ & $\geq 65-<75$ & $\geq 75$ & $<\mathbf{4 0}$ & $\geq \mathbf{4 0}-<\mathbf{6 0}$ & $\geq 60$ & $\mathbf{U}$ & $<\mathbf{3 0}$ & $\geq \mathbf{3 0}-<\mathbf{5 0}$ & $\geq \mathbf{5 0}$ & $\mathbf{U}$ \\
\hline TKA & 3 & 19 & 2 & 7 & 13 & 0 & 11 & 10 & 1 & I & 2 & 17 & 2 \\
\hline THA & 4 & 6 & 5 & 3 & 2 & 0 & 4 & 6 & 0 & 0 & 0 & 10 & 0 \\
\hline HFS & I & 7 & 0 & I & 7 & I & 5 & 2 & 0 & 0 & 2 & 5 & I \\
\hline$U$ & I & I & 0 & I & I & 0 & 0 & 0 & 2 & 0 & 0 & 0 & 2 \\
\hline Total & 9 & 33 & 7 & 12 & 23 & I & 20 & 18 & 3 & I & 4 & 32 & 5 \\
\hline Percentage $^{a}$ & 21.4 & 78.6 & 16.7 & 28.6 & 54.8 & 2.4 & 47.6 & 42.9 & 7.1 & 2.4 & 9.5 & 76.2 & 11.9 \\
\hline
\end{tabular}

Note: ${ }^{a}$ The percentage may not total $100 \%$ due to rounding.

Abbreviations: $\mathrm{CL}_{\mathrm{CR}}$, creatinine clearance; $\mathrm{M}$, male; $\mathrm{F}$, female; $U$, unknown; TKA, total knee arthroplasty; THA, total hip arthroplasty; HFS, hip fracture surgery. 
of edoxaban for the prevention of VTE in patients undergoing orthopedic surgery. In these trials, ADRs (including laboratory abnormalities) were reported in $38.8 \%$ of patients treated with edoxaban. ${ }^{9}$ Common ADRs reported included bleeding events in $16.8 \%$ of patients (for example, hematuria [ $4.9 \%$ ], subcutaneous hemorrhage [4.9\%], and wound hemorrhage [2.8\%]), increased $\gamma$-glutamyl transpeptidase in $9.9 \%$ of patients, and increased alanine aminotransferase (glutamate pyruvate transaminase) in $6.4 \%$ of patients.

In pooled analyses of the Phase III STARS E- ${ }^{16}$ and STARS $\mathrm{J}-5^{16}$ trials in patients undergoing TKA and THA, similar incidences of major and clinically relevant nonmajor (CRNM) bleeding events with edoxaban compared to enoxaparin were observed ( $4.6 \%$ versus $3.7 \%$, respectively; $P=0.427$ ) and subgroup analyses indicated there were no significant differences between edoxaban and enoxaparin in any subgroup, including age, weight, or $\mathrm{CL}_{\mathrm{CR}}{ }^{22}$ In the STARS J-5 study evaluating patients undergoing elective THA, the incidence of major and CRNM bleeding events was $2.6 \%$ in the edoxaban group, and $3.7 \%$ in the enoxaparin group. ${ }^{15}$ In STARS E-3, a study on patients following elective TKA, the incidence of major and CRNM bleeding events in the edoxaban group was $6.2 \%$, and $3.7 \%$ in the enoxaparin group. ${ }^{16}$ In addition, the STARS J-4 study in HFS patients showed that the incidence of major and CRNM bleeding was 3.4\% in the edoxaban group and $6.9 \%$ in the enoxaparin group. ${ }^{17}$

There are limitations to our study. First, compared to a controlled clinical trial where ADRs are actively monitored and collected, our study is a postmarketing surveillance study, in which the nature of collecting ADRs is done by voluntary reporting. Therefore, the number of bleeding events reported and described in this manuscript is limited to those who voluntarily reported ADRs. Second, the true denominator of patients who received edoxaban treatment during the EPPV period is unknown. Therefore, the exact bleeding rate during the EPPV period cannot be extrapolated from these data, and compared directly to the edoxaban bleeding rates from controlled clinical trials.

In conclusion, the early safety data from the EPPV period in Japan is consistent with the known safety profile of edoxaban therapy for prevention of VTE in patients undergoing major orthopedic surgery and did not identify any unforeseen safety signals.

\section{Acknowledgments}

Editorial support was provided by Courtney Zeni, $\mathrm{PhD}$, and Meryl Gersh, PhD, of AlphaBioCom, LLC (King of Prussia, PA), and funded by Daiichi Sankyo.

\section{Disclosure}

All authors are employees of Daiichi Sankyo Company, Limited (Tokyo, Japan), which manufactures and markets edoxaban in Japan. The authors report no other conflicts of interest in this work.

\section{References}

1. Spencer FA, Emery C, Lessard D, et al. The Worcester Venous Thromboembolism study: a population-based study of the clinical epidemiology of venous thromboembolism. J Gen Intern Med. 2006;21(7):722-727.

2. Sudo A, Sano T, Horikawa K, Yamakawa T, Shi D, Uchida A. The incidence of deep vein thrombosis after hip and knee arthroplasties in Japanese patients: a prospective study. J Orthop Surg (Hong Kong). 2003;11(2):174-177.

3. National Institute for Health and Clinical Excellence. Venous Thromboembolic Diseases: The Management of Venous Thromboembolic Diseases and the Role of Thrombophilia Testing. Manchester, UK: National Institute for Health and Clinical Excellence; 2012.

4. Weitz JI, Eikelboom JW, Samama MM; American College of Chest Physicians. New Antithrombotic Drugs: Antithrombotic Therapy and Prevention of Thrombosis. 9th ed: American College of Chest Physicians Evidence-Based Clinical Practice Guidelines. Chest. 2012;141(Suppl 2):e120S-e151S.

5. Sørensen HT, Horvath-Puho E, Pedersen L, Baron JA, Prandoni P. Venous thromboembolism and subsequent hospitalisation due to acute arterial cardiovascular events: a 20-year cohort study. Lancet. 2007;370(9601):1773-1779.

6. Galioto NJ, Danley DL, Van Maanen RJ. Recurrent venous thromboembolism. Am Fam Physician. 2011;83(3):293-300.

7. Falck-Ytter Y, Francis CW, Johanson NA, et al; American College of Chest Physicians. Prevention of VTE in Orthopedic Surgery Patients: Antithrombotic Therapy and Prevention of Thrombosis. 9th ed: American College of Chest Physicians Evidence-Based Clinical Practice Guidelines. Chest. 2012;141(Suppl 2):e278S-e325S.

8. Geerts WH, Bergqvist D, Pineo GF, et al; American College of Chest Physicians. Prevention of Venous Thromboembolism: American College of Chest Physicians Evidence-Based Clinical Practice Guidelines. 8th ed. Chest. 2008;133(Suppl 6):381S-453S.

9. Lixiana [package insert]. Tokyo, Japan: Daiichi Sankyo Company, Ltd; 2011

10. Raskob G, Büller H, Prins M, et al. Edoxaban for the long-term treatment of venous thromboembolism: rationale and design of the Hokusaivenous thromboembolism study - methodological implications for clinical trials. J Thromb Haemost. 2013;11(7):1287-1294.

11. Ruff CT, Giugliano RP, Antman EM, et al. Evaluation of the novel factor Xa inhibitor edoxaban compared with warfarin in patients with atrial fibrillation: design and rationale for the Effective aNticoaGulation with factor xA next GEneration in Atrial Fibrillation-Thrombolysis In Myocardial Infarction study 48 (ENGAGE AF-TIMI 48). Am Heart $J$. 2010;160(4):635-641.

12. Furugohri T, Isobe K, Honda Y, et al. DU-176b, a potent and orally active factor Xa inhibitor: in vitro and in vivo pharmacological profiles. J Thromb Haemost. 2008;6(9):1542-1549.

13. Fuji T, Fujita S, Tachibana S, Kawai Y. A dose-ranging study evaluating the oral factor $\mathrm{Xa}$ inhibitor edoxaban for the prevention of venous thromboembolism in patients undergoing total knee arthroplasty. J Thromb Haemost. 2010;8(11):2458-2468.

14. Raskob G, Cohen AT, Eriksson BI, et al. Oral direct factor Xa inhibition with edoxaban for thromboprophylaxis after elective total hip replacement. A randomised double-blind dose-response study. Thromb Haemost. 2010;104(3):642-649.

15. Fuji T, Fujita S, Tachibana S, et al. Efficacy and safety of edoxaban versus enoxaparin for the prevention of venous thromboembolism following total hip arthroplasty: STARS J-V trial [Abstract]. Blood. 2010;116:3320. 
16. Fuji T, Wang CJ, Fujita S, et al. Edoxaban versus enoxaparin for thromboprophylaxis after total knee arthroplasty: the STARS E-3 trial [Abstract]. Pathophysiol Haemost Thromb. 2010;37:OC297.

17. Fujita S, Fuji T, Tachibana S, Nakamura M, Kawai Y. Safety and efficacy of edoxaban in patients undergoing hip fracture surgery [Abstract]. Pathophysiol Haemost Thromb. 2010;37:P366.

18. Ministry of Health, Labor and Welfare. [Guidelines for Implementation of Early Post-Marketing Phase Vigilance (EPPV) for Prescription Drugs]. 2006. Japanese. Available from http://www.info.pmda.go.jp/ shinyaku/file/s20060324-001.pdf. Accessed on September 11, 2013.

19. International Federation of Pharmaceutical Manufacturers and Associations. Medical Dictionary for Regulatory Activities. MedDRA/J Version 14.1. 2011. Available from: http://www.meddra.org/sites/ default/files/guidance/file/intguide_14_1_english.pdf. Accessed September 11, 2013.

20. International Conference on Harmonisation of Technical Requirements for Registration of Pharmaceuticals for Human Use. ICH Harmonised Tripartite Guideline. Post-Approval Safety Data Management: Definitions and Standards for Expediting Reporting E2D. Geneva, Switzerland: International Conference on Harmonisation; 2003. Available from: http://www.ich.org/fileadmin/Public_Web_Site/ ICH_Products/Guidelines/Efficacy/E2D/Step4/E2D_Guideline.pdf. Accessed April 3, 2013.
21. Nagase $Y$, Yasunaga $H$, Horiguchi $H$, et al. Risk factors for pulmonary embolism and the effects of fondaparinux after total hip and knee arthroplasty: a retrospective observational study with use of a national database in Japan. J Bone Joint Surg Am. 2011;93(24):e146.

22. Fuji T, Fujita S, Tachibana S, Kawai Y. Edoxaban versus enoxaparin for the prevention of venous thromboembolism: pooled analysis of venous thromboembolism and bleeding from STARS E-3 and STARS J-V. Blood. 2011;118(21):208. Available from: https://ash.confex.com/ ash/2011/webprogram/Paper39023.html. Accessed September 11, 2013.

23. Kuroda Y, Hotoda H, Nishikawa Y, Nishiwaki A. Post-Marketing Safety Experience with Edoxaban in Japan for Thromboprophylaxis Following Major Orthopedic Surgery. Blood. 2012;120: 4697(Abstract). Available from: http://abstracts.hematologylibrary.org/cgi/content/ abstract $/ 120 / 21 / 4697$ ? maxtoshow $=\&$ hits $=10 \&$ RESULTFORMAT $=\&$ fulltext $=$ post-marketing \& searchid $=1 \&$ FIRSTINDEX $=0 \&$ volume $=12$ $0 \&$ issue $=21 \&$ resourcetype $=$ HWCIT. Accessed September 27, 2013.
Vascular Health and Risk Management

\section{Publish your work in this journal}

Vascular Health and Risk Management is an international, peerreviewed journal of therapeutics and risk management, focusing on concise rapid reporting of clinical studies on the processes involved in the maintenance of vascular health; the monitoring, prevention and treatment of vascular disease and its sequelae; and the involvement of

\section{Dovepress}

metabolic disorders, particularly diabetes. This journal is indexed on PubMed Central and MedLine. The manuscript management system is completely online and includes a very quick and fair peer-review system, which is all easy to use. Visit http://www.dovepress.com/ testimonials.php to read real quotes from published authors. 